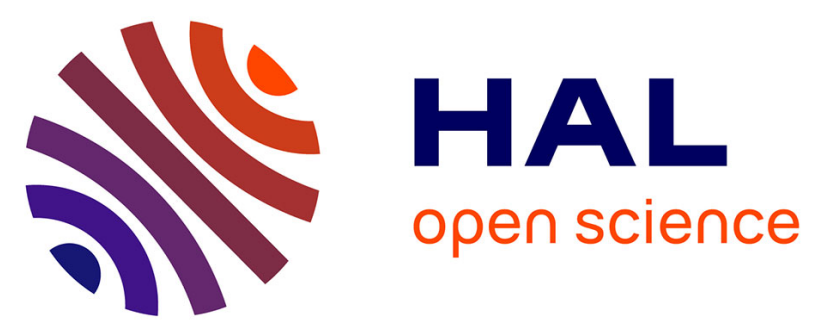

\title{
Enhancement of linear and nonlinear optical properties of deoxyribonucleic acid-silica thin films doped with rhodamine
}

Bouchta Sahraoui, Mindaugas Pranaitis, Konstantinos Iliopoulos, Maria Mihaly, Alina Comanescu, Mirela Moldoveanu, Ileana Rau, Vaidotas

Kažukauskas

\section{To cite this version:}

Bouchta Sahraoui, Mindaugas Pranaitis, Konstantinos Iliopoulos, Maria Mihaly, Alina Comanescu, et al.. Enhancement of linear and nonlinear optical properties of deoxyribonucleic acid-silica thin films doped with rhodamine. Applied Physics Letters, 2011, 99 (24), pp.243304. 10.1063/1.3669406 . hal-01389334

\section{HAL Id: hal-01389334 \\ https://hal.science/hal-01389334}

Submitted on 8 Oct 2021

HAL is a multi-disciplinary open access archive for the deposit and dissemination of scientific research documents, whether they are published or not. The documents may come from teaching and research institutions in France or abroad, or from public or private research centers.
L'archive ouverte pluridisciplinaire HAL, est destinée au dépôt et à la diffusion de documents scientifiques de niveau recherche, publiés ou non, émanant des établissements d'enseignement et de recherche français ou étrangers, des laboratoires publics ou privés. 


\title{
Enhancement of linear and nonlinear optical properties of deoxyribonucleic acid-silica thin films doped with rhodamine
}

\author{
Bouchta Sahraoui, ${ }^{1}$ Mindaugas Pranaitis, ${ }^{1,2}$ Konstantinos Iliopoulos, ${ }^{1}$ Maria Mihaly, ${ }^{3, a)}$ \\ Alina F. Comanescu, ${ }^{3}$ Mirela Moldoveanu, ${ }^{3}$ Ileana Rau, ${ }^{3}$ and Vaidotas Kažukauskas ${ }^{2}$ \\ ${ }^{1}$ MOLTECH ANJOU, University of Angers, CNRS UMR 6200, F-49045 Angers, France \\ ${ }^{2}$ Department of Semiconductor Physics and Institute of Applied Research of Vilnius University, \\ Sauletekio al. 9, Bld. 3, LT-10222 Vilnius, Lithuania \\ ${ }^{3}$ University Politechnica Bucharest, Faculty of Applied Chemistry and Material Science, \\ 1 Polizu, 01160 Bucharest, Romania
}

(Received 28 September 2011; accepted 19 November 2011; published online 13 December 2011)

\begin{abstract}
In this work, we present the linear and nonlinear optical properties of DNA as functional material, incorporated into a silica material matrix with rhodamine organic dye. We observed that even low concentration of DNA affects the aggregate behavior of the dyes in silica films. The samples with DNA showed higher transmittance and fluorescence efficiency. Moreover, the presence of DNA has been found to significantly enhance the nonlinear optical response of the systems. In this way, we prove that silica materials can provide suitable matrices for hybridization with functional molecules and can be utilized as active optical waveguide materials with enhanced nonlinear optical properties. (c) 2011 American Institute of Physics. [doi:10.1063/1.3669406]
\end{abstract}

The unique double-helix structure of deoxyribonucleic acid (DNA) results in optical and electronic properties that are extremely interesting for developing functional elements for photonic applications. ${ }^{1,2}$ The systems based on biological molecules often show superior properties, as compared to conventional organic or inorganic materials. In addition, the natural biomaterials are inherently biodegradable and from renewable resources.

DNA has been investigated as a material for fabricating photonic and optoelectronic devices. ${ }^{3,4}$ Some lumophores such as the fluorescent dye rhodamine 6G (Rh6G) intercalated in DNA result in amplified spontaneous emission from the Rh6G-DNA-surfactant complex. ${ }^{5,6}$ Moreover, this dye was incorporated into silica materials in order to be used in tunable solid-state lasers. ${ }^{7}$ Different organic dyes were incorporated into sol-gel matrices for the preparation of optically transparent materials with third-order non-linear optical properties. Large third-order optical nonlinearities and fast response were measured in sol-gel derived materials doped with azo-dyes, ${ }^{8}$ cyanine, as well as rhodamine and coumarins. ${ }^{9}$ The organic-inorganic hybrid host matrices are superior in terms of thermal and mechanical stability, ${ }^{10}$ also they are highly transparent. Moreover, the dopants maintain their original optical and magnetic properties inside the silica matrix. ${ }^{11}$ Small concentrations of the molecules can radically change the structure of the hybrid organic-inorganic materials, thus strongly influencing their properties.

The investigation of the nonlinear optical (NLO) properties of such organic-inorganic hybrid materials are of substantial interest in terms of creating low-temperature technology for optical fiber production, as well as for other various, important photonic applications. Silica materials can provide excellent matrices for hybridization with functional molecules

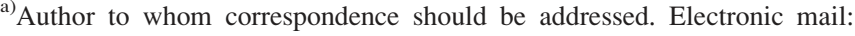
maria.mihaly@gmail.com.
}

and nanomaterials, which can provide the necessary optical properties in order to match the needs of specific photonic applications.

The aim of this work was the investigation of the linear and nonlinear optical properties of DNA-silica/rhodamine thin films, as they are promising systems for optical waveguide applications. The thin films were characterized by means of UV-Vis spectroscopy and third harmonic generation (THG) measurements. All experiments were performed at room temperature.

The DNA-silica materials were prepared using DNA aqueous solutions of $1.0 \mathrm{mg} / \mathrm{ml}$ with different rhodamine dye concentrations (from $0.007 \%$ to $0.060 \%$ ), by using Water/ TX-114/pinus oil microemulsion system as template. The DNA-silica thin films were directly synthesized by microemulsion assisted sol-gel dip-coating on glass substrates. The thickness of the films has been in all cases precisely measured by means of a micrometer. The thickness was in all cases found to be around $0.3 \mathrm{~mm}$, while small deviations, which were unavoidable with the aforementioned preparation technique, have been taken into account during the analysis of the experimental results for the determination of the nonlinear optical parameters. The detailed experimental synthesis procedure was described elsewhere. ${ }^{12}$ In short, the DNA/water solution was solubilised in a water/oil microemulsion through vigorous stirring and then was encapsulated into a silica matrix in acidic media. These hybrid materials were water-insoluble. This approach is unique as compared to the conventional methods involving adsorption on glass surface, entrapment in polymer matrix or impregnation in porous glass powders, because entrapment is based on the forming of the silica network around the functional molecules within the microemulsions colloidal aggregates.

The prepared films were characterized by transmittance and diffuse reflectance UV-Vis measurements. The fluorescence and UV-Vis transmittance spectra of the samples were 


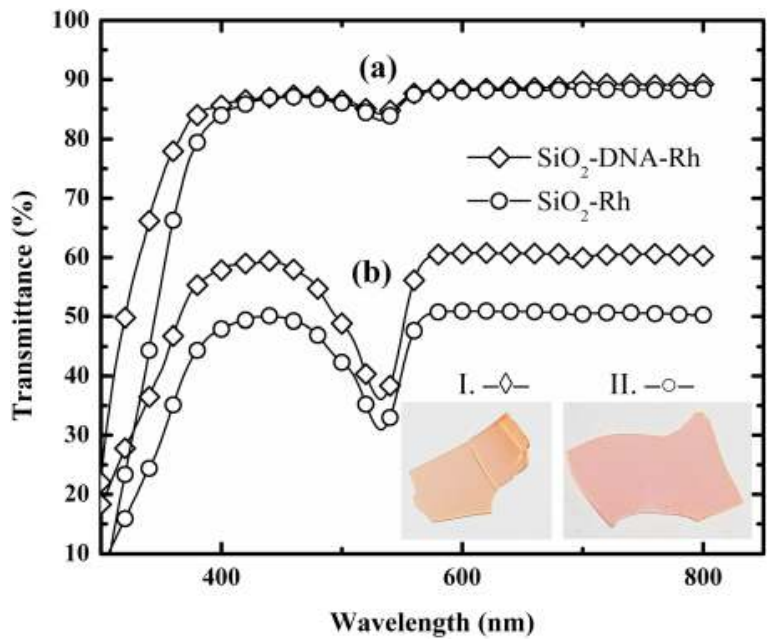

FIG. 1. (Color online) UV-Vis transmittance spectra of thin films, exhibiting low $-0.007 \%$ (a) and higher- $-0.060 \%$ (b) concentration of the dye. The pictures I and II in the inset correspond to the DNA doped and non-doped samples.

recorded within the range of 300 and $800 \mathrm{~nm}$ by using a JASCO V-550 Spectrophotometer and a JASCO FP-6500 Spectrofluorometer, respectively. The transmittance spectra are presented in Fig. 1. The absorption maximum at $532 \mathrm{~nm}$ confirms the presence of rhodamine, homogeneously distributed in the silica or DNA-silica matrices. The same absorption maximum was observed in DNA doped rhodamine $6 \mathrm{G}$ solution in polyvinyl alcohol. ${ }^{13}$ The maximum between $530-540 \mathrm{~nm}$ corresponds to absorption by the free Rh6G monomer. ${ }^{14}$ The curves indicated as (a) and (b) in Fig. 1 correspond to $0.007 \%$ and $0.060 \%$ concentration of dye, respectively. It is obvious that by increasing the dye concentration, the transparency of the films is reduced. However, the presence of DNA slightly improves their transparency as it can be seen in the same figures, as well as in the inset of Fig. 1. This may be explained by the location of the dye molecules. When small dye concentrations are used, the molecules are located in the DNA groves. On the contrary at high concentrations, they appear in the DNA groves but they are also associated with the surfactant oxyethilenic groups. Intensification of the fluorescence lines shown in Fig. 2 also supports this conclusion. In many cases, the dyes act as fluorescent labels for bio-molecules and can interact with the biomolecule either through covalent or non-covalent bonding. Moreover, fluorescence dyes, that bind to double helical DNA by intercalation or groove binding, reduce the fluorescence quenching caused by aggregation ${ }^{15,16}$ or the rate of the nonradiative transitions from the excited state. ${ }^{17}$

The NLO properties of the films were analyzed by the third harmonic generation technique. The measurements were performed in the air by the Maker fringes technique, ${ }^{18}$ using a diode pumped passively mode-locked $\mathrm{Nd}: \mathrm{YVO}_{4}$ laser, working at $1064 \mathrm{~nm}$ with $30 \mathrm{ps}$ pulse duration and $10 \mathrm{~Hz}$ repetition rate. The Maker fringes are the interference patterns obtained by the rotation of the plane parallel to the sample under the excitation of a laser beam of fixed direction. The interference arises from the superposition of the free and the bound harmonic polarization waves generated in the medium by the

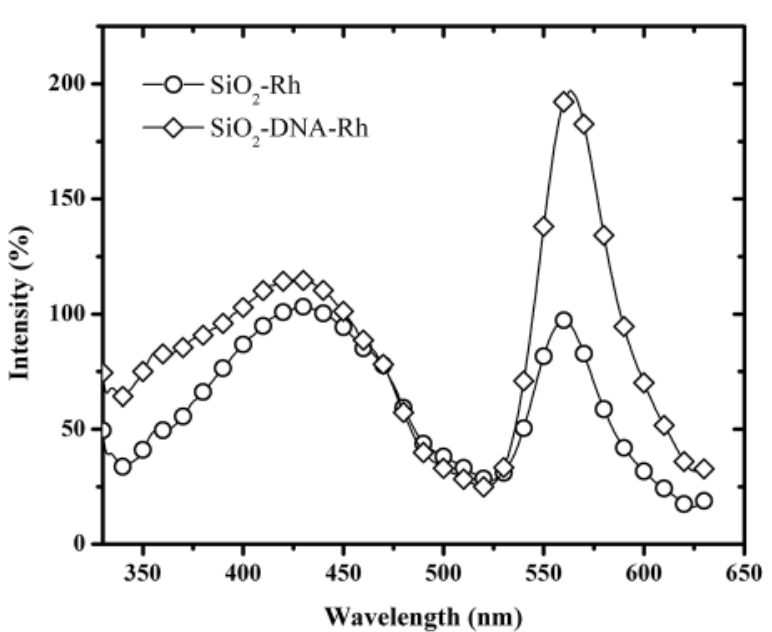

FIG. 2. Fluorescence spectra of the rhodamine-silica thin films in absence/ presence of DNA.

nonlinear interaction with the pump beam. The third harmonic signal (generated by the sample) at $355 \mathrm{~nm}$ was filtered by selective filters and detected with an appropriate photomultiplier. A fused silica plate was used as a reference material for the THG measurements, due to the well-known nonlinear susceptibility it exhibits $\left(\chi_{\text {silica }}^{(3)}=2.0 \times 10^{-22} \mathrm{~m}^{2} / \mathrm{V}^{2}\right){ }^{19}$ The advantage of the THG technique is that it provides information related only with the electronic contribution to the nonlinearity $\left(\chi_{\text {elec }}^{(3)}\right)$, while it is not affected by other contributions (e.g., rotational, redistribution, etc.).

For the investigation of the nonlinear optical response, several Maker fringes patterns have been recorded. In order to characterize the nonlinear optical parameters, the experimental data have been analyzed, taking into account also the significant harmonic absorption loss (Fig. 1) using the procedure described elsewhere. ${ }^{20-22}$

The THG measurements have yielded interesting results. The samples have been found to be THG efficient, while the nonlinear optical signal was highly dependent upon the angle of incidence of the laser beam with respect to the sample, resulting to Maker fringes patterns. In Fig. 3, characteristic experimental curves corresponding to the Silica-Rh and

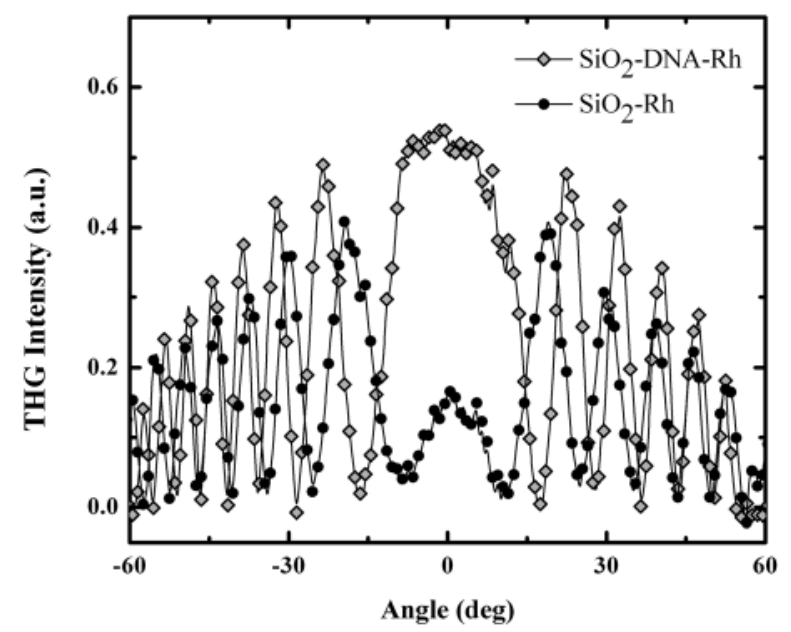

FIG. 3. An example of the THG Maker fringes signals as a function of the incident angle in the case of the silica-Rh and silica-DNA-Rh systems. 
TABLE I. Third order nonlinear susceptibility values for the investigated compounds.

\begin{tabular}{lcc}
\hline \hline Sample & $\begin{array}{c}\text { Thickness } \\
\left(10^{-2} \mathrm{~cm}\right)\end{array}$ & $\chi_{\text {elec }}^{(3)}\left(\times 10^{-22} \mathrm{~m}^{2} / \mathrm{V}^{+2}\right)$ \\
\hline $\mathrm{SiO}_{2}$-DNA $(0.15 \%)-\mathrm{Rh}(0.007 \%)$ & 3.4 & $12.5 \pm 0.2$ \\
$\mathrm{SiO}_{2}$-Rh $(0.007 \%)$ & 3.0 & $5.6 \pm 0.1$ \\
Fused silica & 0.1 & 2.0 \\
\hline \hline
\end{tabular}

Silica-DNA-Rh samples, obtained under the same experimental conditions, for comparison reasons are presented. The period of the Maker-fringes patterns has been found to be directly dependent upon the sample thickness as expected. In Table I, the nonlinear optical parameters of the investigated compounds can be seen. For comparison reasons, the response of fused silica is also added in the same table. The $\chi^{(3)}$ values obtained for the films are higher than that of fused silica by about a factor of 6 and 3 for the DNA-doped and the non-doped samples, respectively. However, what is very important is that the silica-DNA-Rh films exhibits significantly higher third order nonlinear susceptibility than the silica-Rh films. As it can be seen from the same table, the increase of the $\chi^{(3)}$ in the case of the sample exhibiting $0.007 \%$ concentration of $\mathrm{Rh}$ and $0.15 \%$ of DNA is higher than $100 \%$ if we compare with the non-doped system. This enhancement of the nonlinear optical response, related to the presence of the DNA can be attributed to the increase of the charge transfer, which takes place in the system and is due to the many highly polarizable conjugated $\pi$ electrons in DNA (Ref. 23) and also in Rh6G-PVA-DNA. ${ }^{13}$ Moreover, the interactions due to intercalation into the base pair stack at the core of the double helix and/or insertion into the minor groove of DNA are well known to have strong impact on the optical characteristics of organic dyes.

In conclusion, the linear and nonlinear optical properties of DNA-silica/rhodamine thin films have been characterized. It was demonstrated that even low concentrations of DNA bio-molecules of about $0.15 \%$ can strongly affect the aggregate behavior of the dyes in silica materials, resulting in significant enhancement of both the linear and nonlinear optical properties of the systems. More specifically, the addition of DNA has been found to result in higher transmittance and fluorescence efficiency, as well as significantly higher third order nonlinearity. Thus, silica materials are suitable matrices for the optical dyes inserted into the double helix of DNA molecules, enabling engineering of active optical waveguide materials with very interesting nonlinear optical properties.

I. Rau would like to acknowledge the POS CCE Project No. 634, SMIS 12575, for financial support through the Contract No. 240/31.08.2010.

${ }^{1}$ T. B. Singh, N. S. Sariciftci, and J. G. Grote, Adv. Polym. Sci. 223, 73 (2010).

${ }^{2}$ E. Heckman, J. A. Hagen, P. P. Yaney, J. Grote, and F. K. Hopkins, Appl. Phys. Lett. 87, 211115 (2005).

${ }^{3}$ A. J. Steckl, Nat. Photonics 1, 3 (2007).

${ }^{4}$ R. Czaplicki, O. Krupka, Z. Essaidi, A. El-Ghayoury, F. Kajzar, J. G. Grote, and B. Sahraoui, Opt. Express 15, 15268 (2007); Nat. Photonics 2, 6 (2008).

${ }^{5}$ Y. Kawabe, L. Wang, S. Horinouchi, and N. Ogata, Adv. Mater. 12, 1281 (2000).

${ }^{6} J$. Mysliwiec, L. Sznitko, S. Bartkiewicz, A. Miniewicz, Z. Essaidi, F. Kajzar, and B. Sahraoui, Appl. Phys. Lett. 94, 241106 (2009).

${ }^{7}$ F. Salin, G. LeSaux, P. Georges, A. Brun, C. Bagnall, and J. Zarzycki, Opt. Lett. 14, 785 (1989).

${ }^{8}$ V. Rosso, J. Loicq, Y. Renotte, and Y. Lion, J. Non-Cryst. Solids 342, 140 (2004).

${ }^{9}$ X. Zhang, Z. Cao, K. Yang, and G. Long, Proc. SPIE 3175, 302 (1998).

${ }^{10}$ Y. Ner, D. Navarathne, D. M. Niedzwiedzki, J. G. Grote, A. V. Dobrynin, H. A. Frank, and G. A. Sotzing, Appl. Phys. Lett. 95, 263701 (2009).

${ }^{11} \mathrm{P}$. Innocenzi and B. Lebeau, J. Mater. Chem. 15, 3821 (2005).

${ }^{12}$ M. Mihaly, A. Comanescu, A. Rogozea, C. Pirvu, and I. Rau, Proc. SPIE 7403, 740308 (2009).

${ }^{13}$ B. Nithyaja, H. Misha, P. Radhakrishnan, and V. P. N. Nampoori, J. Appl. Phys. 109, 023110 (2011).

${ }^{14}$ R. Vogel, P. Meredith, M. D. Harvey, and H. Rubinsztein-Dunlop, Spectrochim. Acta, Part A 60, 245 (2004).

${ }^{15}$ B. A. Armitage, Top. Curr. Chem. 253, 55 (2005).

${ }^{16}$ P. N. Prasad, Introduction to Biophotonics (John Wiley \& Sons, New York, 2003), pp. 545-557.

${ }^{17}$ F. Ito, T. Kakiuchi, and T. Nagamura J. Phys. Chem. C 111, 6983 (2007).

${ }^{18}$ P. Maker, R. Terhune, M. Nisenoff, and C. Savage, Phys. Rev. Lett. 8, 21 (1962).

${ }^{19}$ F. Kajzar, Y. Okada-Shudo, C. Meritt, and Z. Kafafi, Synthetic Met. 117, 189 (2001).

${ }^{20}$ R. W. Boyd, Nonlinear Optics (Academic, New York, 2003).

${ }^{21}$ A. N. Naumov, D. A. Sidorov-Biryukov, A. B. Fedotov, and A. M. Zheltikov, Opt. Spectrosc. 90, 778 (2001).

${ }^{22}$ B. Sharaoui, J. Luc, A. Meghea, R. Czaplicki, J.-L. Fillaut, and A. Migalska-Zalas, J. Opt. A, Pure Appl. Opt. 11, 024005 (2009).

${ }^{23}$ O. Krupka, A. El-Ghayoury, I. Rau, B. Sahraoui, J. G. Grote, and F. Kajzar, Thin Solid Films 516, 8932 (2008). 